gewohnheiten eines Patienten für das Diabetesmanagement sind“, so Al-Rubeaan. Auch die Bedeutung der Blutdruck- und Lipid-Einstellung sei meist klar. Allerdings sehe das bei der Frage nach den beruflichen Aktivitäten und den kulturellen Gegebenheiten schon anders aus. Das Thema „Diabetesmanagement in Fastenzeiten“ werde von den Ärzten in manchen Ländern zu selten angesprochen. Eher ungünstig fielen die Ergebnisse etwa in Deutschland aus: Fast 70\% der Ärzte gaben an, ihre Patienten nicht oder nur manchmal auf das religiöse Fasten hin anzusprechen. Da die Therapie oft nicht angepasst werde, hätten viele Patienten nach der Fastenperiode die Blutzuckerkontrolle verloren oder kämen mit Komplikationen, bedauerte Al-Rubeaan. Er machte darauf aufmerksam, dass Fastenzeiten auch außerhalb des Islam praktiziert werden, und dass die Angaben zu Therapie-Empfehlungen für diese Zeiten international sehr unterschiedlich sind. Al-Rubeaan sprach sich für eine modifizierte Medikation und den Gebrauch von Protokollen mit Regeln für Fastenzeiten aus, vor allem um Hypoglykämien zu vermeiden.

Patienten wünschen sich mehr Infos zu Hypoglykämien Weitere wichtige Ergebnisse der Befragung aus Patientensicht stellte Dr. Rosario Arechavaleta aus Guadelajara/Mexiko vor: 53\% der Patienten gaben an, schon mindestens einmal Hypo- glykämiesymptome empfunden zu haben, aber nur 37\%, dass sie das Thema in einem Routinegespräch mit ihrem Arzt angesprochen hätten. In 44\% der Fälle waren die Hypoglykämien in ihrer Arbeitszeit aufgetreten. Allerdings hatten $76 \%$ nie mit ihrem Arzt über ihre Arbeitsbedingungen gesprochen. 31\% gaben zudem an, ihr Arzt hätte nie erwähnt, wie sie ihr Hypoglykämierisiko senken könnten.

Arechavaleta leitete daraus folgende Schlüsse ab: Es ist nötig, die Therapie individueller zu gestalten. Ärzte und Patienten müssten dazu alle wichtigen Lebensumstände erörtern, die das Blutzuckermanagement beeinflussen könnten. Die Medikationsoptionen werden mit den Patienten nicht immer besprochen und viele wünschen sich mehr Informationen inklusive Vermeidung von Hypoglykämien.

Als Hilfe für Patienten gibt es eine Lifestyle-Checkliste mit allen Informationen, die beim Arzt angesprochen werde sollten. Sie kann über das Unternehmen MSD angefordert werden.

Sarah L. Pampel, München

1. Inzucchi SE, Bergenstal RM, Buse JB et al. Diabetes Care 2012;35(6):1364-79.

Quelle: Pressegespräch am 3.10.2012 beim EASD-Kongress in Berlin, Veranstalter: MSD

Verlust der Betazellfunktion

\title{
Vielleicht sind sie gar nicht tot
}

\begin{abstract}
Sind die meisten Betazellen bei Manifestation eines Typ-2-Diabetes gar nicht zerstört, sondern nur reversibel entdifferenziert? Diese Frage stellt sich, nachdem ein Forscherteam aus den USA am Mausmodell einige interessante Entdeckungen gemacht hat.
\end{abstract}

Nicht sehr häufig wird in den Pressekonferenzen der EASD-Jahrestagung über Mäusestudien berichtet, schon gar nicht, wenn sie aus den USA stammen. Handelt es sich aber um Entdeckungen, die in Zukunft einen völlig neuen Therapieansatz bei Typ1- und Typ-2-Diabetes erschließen könnten, kann das schon mal passieren. So geschehen in diesem Jahr, und zwar von Professor Michele Solimena von der Universität Dresden. Er stellte eine kürzlich publizierte Studie von Dr. Chutima Talchai (Columbia University Medical Center (CUMC) New York) vor, die nahelegt, dass die meisten Betazellen bei der Manifestation eines Typ-2-Diabetes gar nicht tot sind, sondern nur kein Insulin mehr produzieren, weil sich ihre Differenzierung verändert hat [1]. Eine Schlüsselfunktion dabei hat das Transkriptionsfaktorprotein FOXO1 (Forkhead Box Protein), das an mehreren Stellen des Zuckerstoffwechsels regulierend wirkt.

Bei metabolischem Stress wie wiederholten Schwangerschaften, im Verlauf der physiologischen Alterung und wohl auch in frühen Diabetesstadien wandert FOXO1 aus dem Zytoplasma in den Zellkern, wo er repliziert wird. Dort verstärkt er unter anderem die Insulinsekretion der Zelle. Hält der Stress an, dekompensiert das System, FOXO1 ist nicht mehr nachweisbar und die Betazelle verwandelt sich in einer Art Vorläuferzelle, die kein Insulin mehr produziert. Ein Teil beginnt sogar Glu- kagon auszuschütten. Es entsteht eine Stoffwechselsituation, die der eines Typ-2-Diabetikers entspricht. Dies konnten Talchai und ihre Kollegen in einem speziellen Mausmodell, das FOXO1 nicht exprimiert, mithilfe von Zelltracing nachweisen.

„Könnte es also sein, dass Typ-2-Diabetes nicht durch die Zerstörung der Betazellen entsteht, sondern durch ihre Dedifferenzierung infolge des Fehlens von FOXO1?", fragte Solimena. Dann müsste nur eine Möglichkeit gefunden werden, die Zellen wieder in ihren ursprünglichen Funktionszustand zu versetzten.

Dies könnte auch für die Therapie bei Typ-1-Diabetes interessant sein, sagte Solimena. Möglicherweise sei die Erholung der Betazellen bei Insulintherapie in der frühen Phase des Typ1-Diabetes („Honeymoon“) auf diese Vorgänge zurückzuführen. „Vielleicht können sich Betazellen bei frühzeitiger Insulintherapie wieder redifferenzieren“, sagte er. Zwar steht die Forschung in diesem Bereich noch ganz am Anfang, aber, so Solimena „immerhin hat es die Studie schon in den Gesundheitsteil der New York Times gebracht.“

Sarah L. Pampel, München

1. Talchai C, Xuan S, Lin HV, Sussel L, Accili D. Cell.2012 Sep 14;150(6):122334. doi: 10.1016/j.cell.2012.07.029.

Quelle: Pressekonferenz am 2.10.2012 beim EASD-Kongress in Berlin 